\title{
Aplicação das Geotecnologias no Plano Municipal de Recursos Hídricos: O Caso de Planaltina do Paraná - Paraná
}

\author{
Maurício Polidoro ${ }^{1}$ \\ Marcelo Gonçalves ${ }^{2}$ \\ ${ }^{1}$ Pós Graduando em Análise e Educação Ambiental em Ciências da Terra \\ Universidade Estadual de Londrina - UEL \\ mauricio_polidoro@yahoo.com.br \\ ${ }^{2}$ Geógrafo, Mestre em Geografia, Meio Ambiente e Desenvolvimento \\ Universidade Estadual de Londrina - UEL \\ marcelogeo@yahoo.com.br
}

\begin{abstract}
.
This papper shows the process of developing the Geographic Information System (GIS) applied to the development of the Municipal Water Resources Plan (PRHI) in the city of Planaltina do Paraná - PR. This Plan is required by the State of Paraná with prosecutors and aims to add the work of all the municipalities for the generation of the State Water Resources Plan. In this case, we'll show the process of development of the Municipal Water Resources focusing on the importance of using geotecnologies for management plans in cities.
\end{abstract}

Palavras-chave: geographic information system, municipal water resources plan, urban management, urba planning, sistema de informações geográficas, plano municipal de recursos hídricos, gestão urbana, planejamento urbano.

\section{Introdução}

O estado do Paraná, por mediação de acordo com a Secretaria Estadual do Meio Ambiente e Ministério Público encaminhou a todos os municípios do Estado um ofício incentivando o desenvolvimento do Plano Municipal de Recursos Hídricos para atender as exigências da lei federal 9.433/1997 e ainda a lei estadual 12.726/1999 numa ação inédita buscando juntamente com todos esses municípios a elaboração do Plano Estadual de Recursos Hídricos.

Na legislação brasileira, Boccasius-Siqueira (2002) aponta que a temática da água foi inicialmente introduzida no Código Civil Brasileiro, em 1916, no artigo 584 que diz “... as construções capazes de poluir ou inutilizar, para o uso ordinário, a água de poço ou a fonte alheia ..." (BOCCASIUS-SIQUEIRA, 2002).

Naquele período, onde o início do Brasil República se deparava com inúmeros problemas referentes à saúde pública principalmente devido à falta de higiene ocasionado pela ausência do saneamento básico e inúmeros decretos foram promulgados como o 16.300 de 31/12/1923 que exigia o afastamento de fábricas e indústrias de locais com ocupação humana objetivando preservar a saúde pública.

Avançando assim, em 10/07/1934 o decreto 24.643 encarrega o Ministério da Agricultura por meio do Código das Águas a controlar e incentivar o aproveitamento industrial das águas, sendo posteriormente tal função sendo exercida pelo órgão recém criado, Departamento Nacional de Águas e Energia Elétrica (DNAEE).

Considerando-se a esfera legislativa como parte associada e integradora das políticas econômicas e desenvolvimentistas do Estado tem-se evidenciado no Brasil, principalmente a partir da década de 1970, um grande esforço em descentralizar as políticas do âmbito federal para o municipal, onde o primeiro é o cursor das regras mais genéricas cabendo aos estados e municípios aplicar, segundo a concepção federal sobre a determinada temática, as exigências 
necessárias para atender anseios e exigências globais visando o desenvolvimento 'sustentável'.

No centro dessa idéia, os marcos legais referente às políticas dos recursos hídricos tem evoluído no país, conforme pode ser visto com a promulgação da Política Nacional de Recursos Hídricos (Lei 9.433/1997), que vem atender as exigências e preocupações do próprio governo brasileiro e pressões internacionais notavelmente após o evento ECO-92, no Rio de Janeiro.

Visando superar a idéia de abundância e infinitude da água no território nacional, um dos principais instrumentos desta Política é a instituição dos Planos de Recursos Hídricos, que devem ser elaborados por bacias hidrográficas e a criação por meio da lei 9.984 de 17 de julho de 2000 da Agência Nacional das Águas, órgão gestor dos recursos hídricos e de domínio da União (MACHADO, 2003).

Evidencia-se então a criação de inúmeras leis estaduais precursoras após essa exigência federal como aponta Machado (2003) os estados de São Paulo e Ceará que institucionalizaram o SGRH-SP (Sistema de Gerenciamento de Recursos Hídricos, em São Paulo) e SIGRH (Sistema Integrado de Gestão de Recursos Hídricos, no Ceará). No estado do Paraná, o acordo entre Ministério Público Federal e a Secretaria Estadual de Meio Ambiente, recomendou por meio de oficio, a todos os municípios deste estado a desenvolver seu próprio Plano Municipal de Recursos Hídricos, objetivando sistematizar detalhadamente características do sistema físico, social e ambiental para a construção do Plano Estadual de Recursos Hídricos.

A partir disto, este artigo mostrará a importância da utilização das tecnologias geográficas no desenvolvimento de planos estratégicos para os municípios, aplicado neste estudo de caso, no município de Planaltina do Paraná.

\section{Geotecnologias Aplicadas aos Recursos Hídricos}

As Geotecnologias englobam diversas técnicas para tratamento e manipulação de dados geográficos, dentre eles o Sensoriamento Remoto, a automação de tarefas cartográficas e os Sistemas de Informação de Geográfica (SIG), que como exemplo podemos citar o SPRING, programa desenvolvido pelo Instituto Nacional de Pesquisa Espacial (INPE) e disponível gratuitamente ou o software pago ArcGIS. (CARVALHO apud PEREIRA 2007, p. 27).

Os diversos Sistemas de Informações Geográficas atualmente disponíveis são utilizados em ramos distintos do conhecimento, mesmo dentro da Geografia a possibilidade de inserção é enorme. O Geoprocessamento permite a manipulação e representação de informações de áreas como da estatística, do planejamento ambiental, rural ou urbano, dos recursos naturais e das próprias características físico-territoriais.

No desenvolvimento do Sistema de Informações Geográficas do Plano de Recursos Hídricos (SIG-PRHI) ou ainda, podendo-se generalizar para o desenvolvimento de qualquer outro SIG aplicado ao gerenciamento de informações, especialmente aqueles utilizados em Prefeituras, o grande número de dados e as diferentes fontes podem tornar-se ao invés de grande utilidade para um objetivo a ser alcançado uma problemática quando se possui um vasto número de dados, porém baixa quantidade de informações.

Neste sentido, torna-se necessário padronizar o formato dos dados e confrontar informações contraditórias sejam através da análise de campo ou ainda levantamentos na própria Prefeitura objetivando uma maior exatidão do trabalho.

O SIG-PRHI do município de Planaltina do Paraná buscou contemplar, conforme o Termo de Referência os seguintes itens: hipsometria; declividade; sub-bacias hidrográficas; grupo de solos; potencial erosivo dos solos; estradas e rodovias; hidrografia; limite municipal; poços outorgados; estação fluviométrica e ainda a delimitação das áreas de preservação permanente conforma a legislação vigente utilizando-se da imagem do satélite LANDSAT 5. 


\section{Geotecnologias Aplicadas ao Plano Municipal de Recursos Hídricos (SIG-PRHI)}

O município de aplicação da proposta, Planaltina do Paraná, está situado em altitude de 515 metros acima do nível do mar, nas coordenadas Latitude $23^{\circ} 02^{\prime} 00^{\prime \prime}$ Hemisfério Sul e Longitude 52 55'00" Oeste de Greenwich com área territorial de $353,8 \mathrm{~km}^{2}$, segundo o IBGE, fazendo limite com os municípios: ao noroeste Loanda, ao nordeste Guairaça, ao oeste Amaporã, ao sul Cidade Gaúcha e Tapira e oeste Santa Mônica.

O Município não possui muitos rios em seu território, sendo que os principais são aqueles que representam os limites do território a sul, leste e oeste.

Existem cinco sub-bacias, sendo que apenas uma está totalmente inserida no município, a sub-bacia do Ribeirão da Saudade (figura 1).

- Sub-bacia do Ribeirão Selma (Extensão do rio principal 39km);

- Sub-bacia do Ribeirão Lica (Extensão do rio principal $51 \mathrm{~km}$ );

- Sub-bacia do Ribeirão Criciúma (Extensão do rio principal 27km);

- Sub-bacia do Ribeirão da Saudade (Extensão do rio principal 18km);

- Sub-bacia do Rio Ivaí (Extensão do rio principal (trecho no município) 20km).

O SIG-PRHI do município de Planaltina do Paraná foi desenvolvido no software ArcGIS 9.3 sendo o tratamento das imagens efetuado no software SPRING 5.0, do INPE. Utilizou-se imagem LANDSAT $5^{1}$ data de passagem de 30/08/2008 para a classificação do uso do solo. As imagens do Shuttle Radar Topography Mission, disponibilizadas pela EMBRAPA ${ }^{2}$ foram utilizadas para desenvolver as cartas de Hipsometria, Declividade, auxiliaram ainda da delimitação das bacias e sub-bacias hidrográficas e a partir destas pode-se delimitar as áreas de preservação permanente conforme a Lei 4.771/65.

Além dessas "camadas", o SIG-PRHI contempla também: a localização da estação fluviométrica, poços outorgados, sistema de abastecimento de água (localidade e redes), sistema de drenagem urbana, aterro sanitário, tipos de vegetação ao longo das APPs, uso do solo, uso do solo rural, potencial erosivo do solo, altura de degradação do solo, grupos de solos e ainda camadas da malha do sistema viário municipal e as principais estradas. A tabela 1 mostra a camada e o respectivo atributo criado, no banco de dados, do SIG-PRHI.

Os dados são oriundos de diversas fontes tais como ITCG (2009), EMBRAPA (2009), INPE (2009), PARANACIDADE (2008), SUDERHSA (2009) e alguns foram criados a partir de informações já existentes ou através de análises em campo ou operações no próprio software. Para compatibilização desses dados de diversas fontes, foi necessário a priori padronizar o sistema de projeções, que neste SIG adotou-se o GCS South American SAD 69 (UTM Zona 22S).

A sistematização do banco de dados criados da forma apresentada na tabela 1 possibilita uma atualização constante dos dados o que facilita no gerenciamento tanto do sistema dos recursos hídricos como para qualquer outro setor de pesquisa ou da própria prefeitura que pode aprimorá-lo com mais informações.

A figura 2 mostra o ambiente SIG-PRHI e a figura 3 um exemplo de consulta ao banco de dados das informações disponíveis.

\footnotetext{
${ }^{1}$ Disponíveis gratuitamente em: http://www.dgi.inpe.br/CDSR/

${ }^{2}$ Disponíveis gratuitamente em: http://www.relevobr.cnpm.embrapa.br/download/index.htm
} 

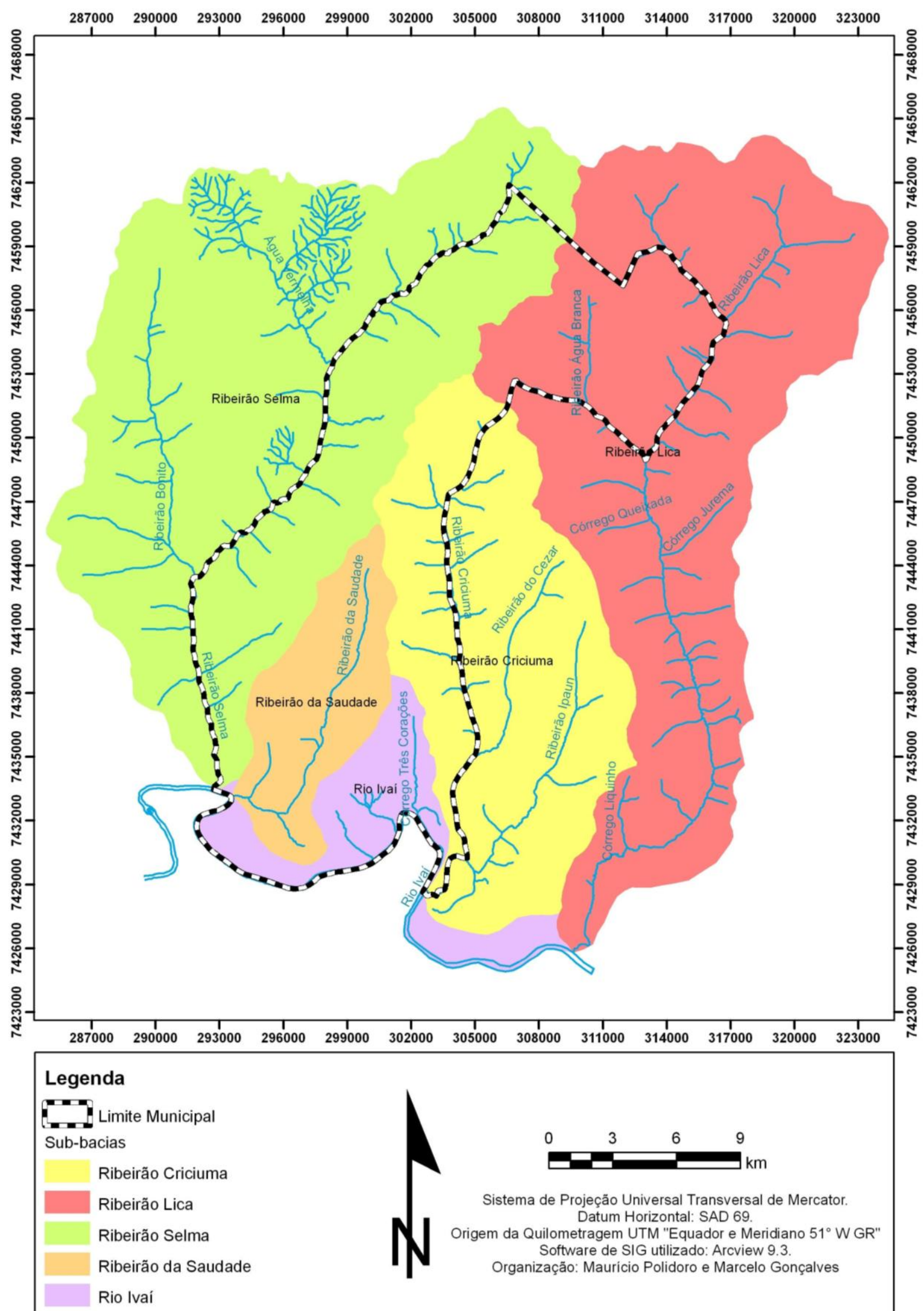

Figura 1. Sub-bacias do município de Planaltina do Paraná.

Fonte: PRH Planaltina do Paraná (2009) 


\begin{tabular}{|l|l|}
\hline \multicolumn{1}{|c|}{ Camada } & \multicolumn{1}{c|}{ Atributos } \\
\hline Captações Supericiais Outorgadas & Nome, Código da Estação \\
\hline Poços Cadastrados na SUDERHSA & Nome do Poço, Código do Poço \\
\hline Hidrografia & $\begin{array}{l}\text { Ordem; sub-bacia; classe de enquadramento, } \\
\text { comprimento do trecho. }\end{array}$ \\
\hline Sistema Viário & Nome de ruas, estradas vicinais, rodovias \\
\hline Rede de Drenagem & Sistema da Drenagem, Cumprimento da Rede \\
\hline Bacias de Drenagem & Area, Tipo da Bacia \\
\hline Destinação dos Resíduos & Área, Tipo \\
\hline Áreas Úmidas & Extensão das Áreas \\
\hline Áreas de Preservação Permanente & Extensão das Áreas \\
\hline Uso do Solo na APP & Tipo de Uso, Área Total \\
\hline Uso e Ocupação do Solo & Tipo de Uso, Área Total \\
\hline Potencial Erosivo do Solo & Classe, Tipo, Aptidão, Área, Potencial Erosivo \\
\hline & $\begin{array}{l}\text { Unidade de mapeamento, classe dos solos, textura, } \\
\text { relevo, clima, vegetação, mecanização, práticas } \\
\text { conservacionistas, área. }\end{array}$ \\
\hline Grupo dos solos & $\begin{array}{l}\text { Nome, escala de vazão mínima, escala de vazão média, } \\
\text { área }\end{array}$ \\
\hline Sub-bacias hidrográficas & Classes \\
\hline Declividade & Classes \\
\hline Hipsometria &
\end{tabular}

Tabela 1. Exemplificação do banco de dados do SIG-PRHI.

Fonte: PRH Planaltina do Paraná (2009)

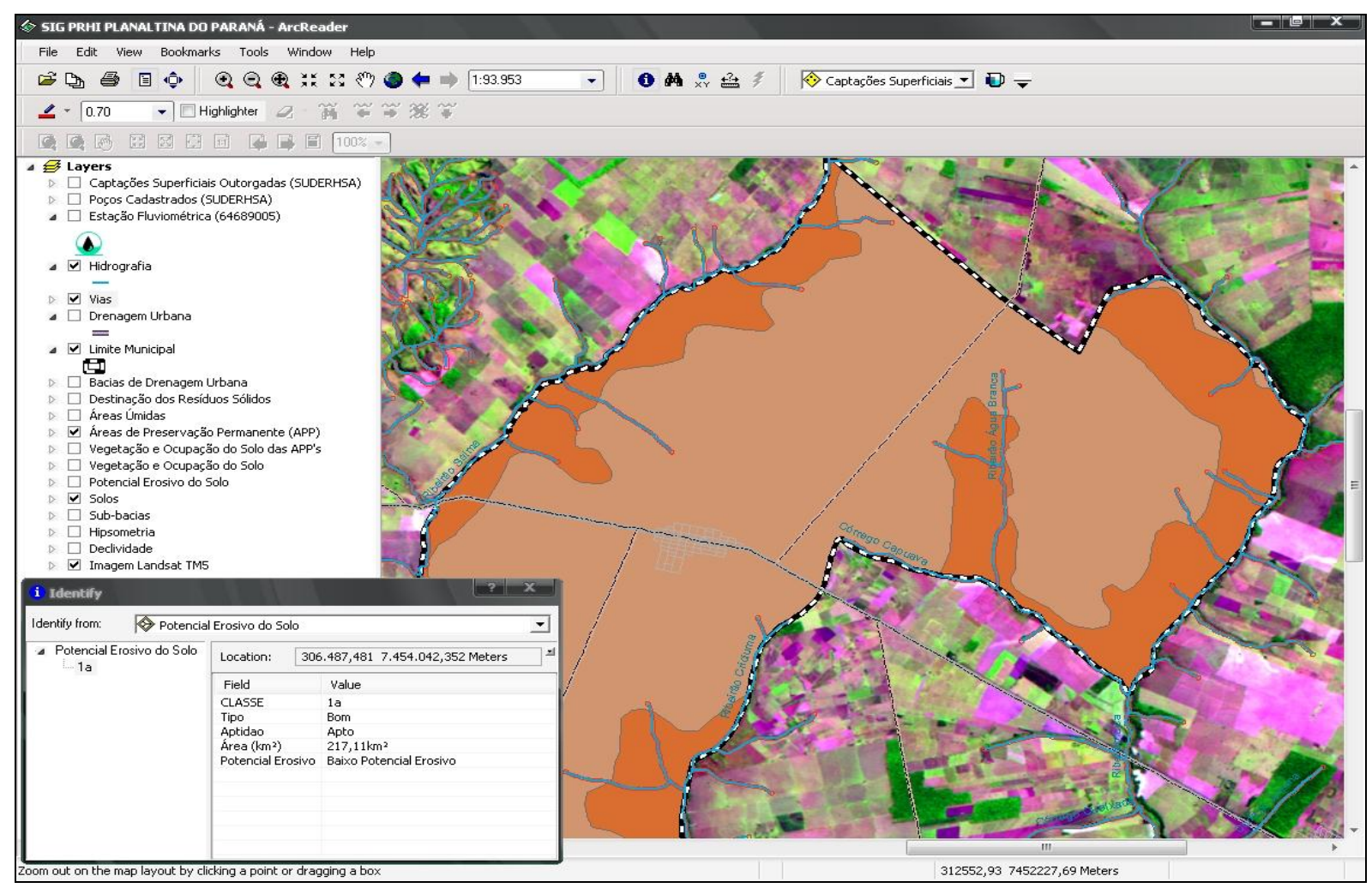

Figura 2. Exemplo de consulta ao banco de dados no SIG-PRHI. 
Fonte: PRH Planaltina do Paraná (2009)

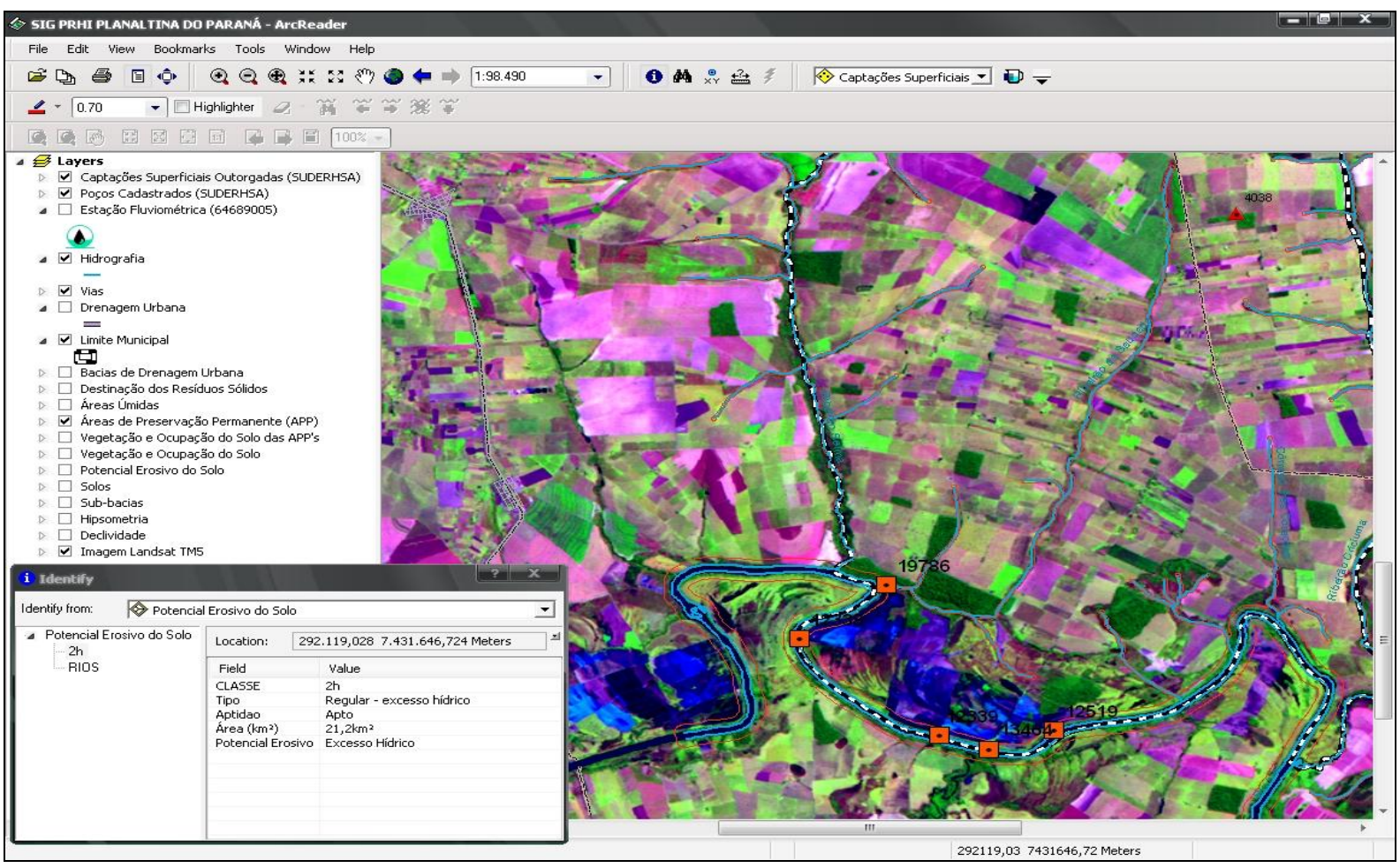

Figura 3. Exemplo de consulta ao banco de dados no SIG-PRHI.

Fonte: PRH Planaltina do Paraná (2009)

\section{Considerações Finais}

A problemática da água tem se tornado cada vez mais recorrente em diversos meios, tanto no técnico-científico quanto na mídia em sua totalidade. O Estado do Paraná, neste sentido, tem-se mostrado pioneiro ao incentivar seus municípios a desenvolverem seus próprios Planos de Recursos Hídricos tornando a temática ambiental uma obrigação nos apontamentos dos administradores públicos.

Contudo, abordar o meio ambiente de forma fragmentada pode levar as análises e intervenções ambientais a grandes catástrofes ao invés de mitigação de possíveis impactos tendo em vista que o ambiente age e funciona de forma integrada e sistêmica e não respeita os limites político-administrativos.

Dessa forma, é altamente recomendável que os municípios utilizem a bacia hidrográfica como unidade de planejamento e gestão do meio urbano e rural, e para a maior eficácia no estabelecimento das diretrizes, proposições e metas em longo prazo no âmbito ambiental isto seja feito em conjunto com outros municípios seguindo os critérios físico-geográficos de cada território.

A partir disso, daí sim as geotecnologias acabam sendo as principais aliadas no desenvolvimento de um diagnóstico completo e coerente com a realidade, desde que as informações utilizadas sejam padronizadas e comprovadas por meio de análises e trabalhos de campo.

No Plano de Recursos Hídricos de Planaltina do Paraná mostrou-se importante o domínio da técnica no sentido da necessidade de padronizar e verificar a fidedignidade dos dados de diversas fontes para que não ocorresse conflito entre si. 
Além disso, a capacitação dos servidores técnicos municipais para a manipulação dessas geotecnologias devem também entrar como prioridade de agenda dos planejadores municipais considerando que o atual estágio da tecnologia não é capaz de se auto-sustentar conforme os eventos no mundo real acontecem.

\section{Referências}

BOCCASIUS-SIQUEIRA, A. O direito ambiental na legislação brasileira - um contributo para o resgate da história. Revista Eletrônica do Mestrado em Educação Ambiental da Universidade Federal do Rio Grande. Volume 9. Julho de 2002.

BRASIL. Lei Federal 9.433 de 8 de janeiro de 1997. Institui a Política Nacional de Recursos Hídricos, cria o Sistema Nacional de Gerenciamento de Recursos Hídricos, regulamenta o inciso XIX do art. 21 da Constituição Federal, e altera o art. $1^{\circ}$ da Lei $n^{\circ} 8.001$, de 13 de março de 1990 , que modificou a Lei $n^{\circ} 7.990$, de 28 de dezembro de 1989.

CÂMARA, G. Conceitos Básicos: Sistema de Informações Geográficas. 1995. Disponível em: < http://www.dpi.inpe.br/teses/lauro/cap2.pdf>. Acesso em: 07 de julho de 2009

INSTITUTO BRASILEIRO DE GEOGRAFIA E ESTATÍSTICA. IBGE Cidades. 2005. Dados sobre município de Planaltina do Paraná. Disponível em: 〈http://www.ibge.gov.br/cidadesat/>. Acesso em 22 de setembro de 2009.

INSTITUTO DE TERRAS, CARTOGRAFIA E GEOCIÊNCIAS DO PARANÁ. Bases cartográficas. Disponível em: < http://www.itcg.pr.gov.br>. Vários acessos em julho e agosto de 2009.

MACHADO, C. J. S. Recursos Hídricos e Cidadania no Brasil: Limites, Alternativas e Desafios. Revista Ambiente \& Sociedade. Volume VI no 2, Julho/Dezembro. 2003.

PEREIRA, Saulo Henrique de Faria et. al. Vigilância do diabetes mellitus na área urbana do município de Viçosa- MG pelo uso de técnicas de Geoprocessamento. Disponível em: < http://cascavel.ufsm.br/revista_ccne/ojs/index.php/cienciaenatura/article/view/50/60>. Acesso em 20 . ago. 2009. PREFEITURA MUNICIPAL DE PLANALTINA DO PARANÁ. Sistema de Informações Geográficas do Plano Municipal de Recursos Hídricos. Volume Final. DVD. 2009.

SECRETARIA ESTADUAL DE DESENVOLVIMENTO URBANO - PARANACIDADE. Bases cartográficas. CD. 2008. 